\title{
The invisibility of gendered power relations in domestic violence policy
}

\section{KAREN M VINCENT MSOCSC(ADMIN) $)^{\star 1}$}

Doctoral Candidate, Faculty of Economics and Commerce, The University of Western Australia, Crawley, Western Australia

\section{JoAN EVELINE PHD}

Associate Professor, Faculty of Economics and Commerce, The University of Western Australia, Crawley, Western Australia

\section{ABSTRACT}

This exploratory study seeks to illustrate how the policy context shapes the way policy actors engage with concepts of gender and practices of racism. The paper draws on two case studies in the context of family and domestic violence (FDV) policy and service development in an Australian State Government context. The first case study uses document analysis of a major public inquiry into Government agency responses to FDV in Indigenous communities. The second uses a policy audit tool to examine a policy development process in a department responsible for coordinating human service agencies, services and funding of community-sector FDV projects. These case studies reveal that both Aboriginal women and non-Aboriginal women can disappear from the concerns that FDV policy purports to solve. To demonstrate our argument, we show how the policy terminology of both 'domestic violence' and that of 'family violence' can render gender and racism invisible.

Key words: gender; racism; family and domestic violence policy; public sector

'Every week in Western Australia police remove around 130 violent people from family homes during domestic violence call-outs, which equates to more than 18 every day. Children and young people live in up to $85 \%$ of these homes.'

(Templeman 2006)

The above statement was made in a speech 1 announcing a program titled 'No more violence: We're breaking the silence' by the State West Australian Government Minister with broad child and family welfare and community development portfolio responsibilities including

* Correspondence to: Ms Karen Vincent, 16402 Bridlewood Rd, Poway, CA 92064, USA; tel: +1 8586765374 ; e-mail: vincek02@student.uwa.edu.au

1. This is an edited version of a paper presented at the Gender, Work and Organization 5th Biennial International Interdisciplinary Conference, Keele University, England, 27-29 June, 2007. The research was funded by an ARC research grant. 
the policy area of family and domestic violence (FDV). The speech was one of many over recent years by government about a subject once considered taboo: family and domestic violence in Aboriginal communities. The Western Australia Parliament has engaged in numerous debates and the Government has responded to frequent media reports about the subject. Increasingly these have been about FDV experienced in Aboriginal communities. In contrast to a history of silence, the past five years has seen the policy context of FDV become highly politicized to the issue. Public sector agencies are under immense pressure, as the Australian public expresses 'moral outrage' (Cripps 2007) about endemic abuse against Aboriginal women and children.

Such outrage is overdue. Indigenous women are 45 times more likely to experience domestic violence than non-Indigenous women and 10 times more likely to be killed as a result of domestic violence (Partnerships Against Domestic Violence 2001). In this context, the pressure is on departments most closely responsible for dealing with family violence against women and children - police, justice and community welfare - to counter and curtail the problem.

This paper examines the complexities and challenges of the public policy process in a fraught and challenging field at a time of turmoil and public visibility. We describe the research as exploratory since it draws on two case studies in one Australian state to examine the extent to which intersectionality is ignored in domestic violence policy. The paper suggests that although the issue of family violence is now much more visible to public scrutiny and departments alike, the crucial issue of the gendered power relations that underpins this family violence remains as invisible as ever when it comes to policy development.

Our two case studies are drawn from the field of FDV in Western Australia. Our analysis of these case studies shows two different ways in which gendered power relations become invisible. The first case, commonly called the 'Gordon
Inquiry', shows how gendered power relations can be omitted from family violence policy when the emphasis of the report is on institutionalized racism. The second shows how Indigenous women disappear in the departmental high-level policy for FDV, but so also does gendered power relations. Both of these public policy documents indicate a lost opportunity to explore intersectionality. Despite this similarity, the capacity of each to confront the white ethnocentrism of family violence policy is quite different.

\section{LITERATURE REVIEW}

The historically and socially contingent nature of policy is particularly relevant in the field of Aboriginal affairs where policies have been critically affected by recent media and public attention. At the same, time feminist studies point to the need for projected gender outcomes to be taken into account in all policy development processes. For some feminists the answer lies in what is now termed 'gender mainstreaming' (Walby 2005). However, as Eveline and Bacchi (2005) noted, that approach to policy is highly contested and subject to being infused with inadequate understandings of gender. As Bacchi (2005: 184) stated, 'the task is to examine how gendered concepts are applied in the lives of diverse groups of men and women'.

Domestic violence is a field of public policy in which one would expect that a gender analysis would be ubiquitous. Yet neither gender nor institutional racism is necessarily given priority in such policymaking. Once considered a taboo subject, domestic violence has become a subject for public and political attention, with the World Health Organization estimating that between $15 \%$ and $71 \%$ of women have experienced physical or sexual assault from an intimate partner (World Health Organization [WHO] 2005: xiii).

Despite gathering pace in the last decade, much domestic violence research has neglected or ignored Indigenous experience. There is signiffcant under-reporting of FDV for all population 
groups, but particularly for Aboriginal women experiencing FDV. Nonetheless, statistical indicators reveal considerable over-representation of Indigenous women experiencing assault and death (Office for Women's Policy 2006). Aboriginal women are 10 times more likely to be murdered than non-Aboriginal women (Duff 1994: 38). In Western Australia, Aboriginal women 'make up only about $3 \%$ of the adult female population (yet) they accounted for half of all the domestic violence incidents reported to the police in 1994 ... (they) are more than 45 times more likely than non-Aboriginal women to be a victim of domestic violence' (Ferrante et al 1996). The Office for Women's Policy (2005: 57) has reported that $22.6 \%$ of Indigenous women in Western Australia perceived family violence as a problem in their community. Despite their continued calls for improved safery and protection, Indigenous women have been described as 'the single most legally disadvantaged group in Australian society' (Australian Law Reform Commission 1994).

The full picture of FDV and its impacts on the social, emotional, physical and financial wellbeing of Indigenous women and communities is currently unmeasured and program evaluations report mixed success with efforts at prevention, intervention, punishment and treatment. The 2007 Social Justice Report (Aboriginal \& Torres Strait Islander Social Justice Commissioner, Human Rights and Equal Opportunity Commission (HREOC) 2007) identified concerns with research and evaluation methods, including the privileging of statistical data by government that ultimately serves to reinforce negative stereotypes. 'One of the challenges that this demonstrates is to listen to communities and ensure that evaluation is conducted in a situational and culturally appropriate way' (HREOC 2007: 22). Understanding the components for 'best practice' is still under-developed. However, common elements at community level include the importance of Aboriginal leadership and Aboriginal women project self-management. It has been of critical importance for the sustainability of Abor- iginal communities to resist racist assumptions that problematise Aboriginal peoples by portraying Aboriginality as the source of FDV problems and presenting a chronic or recalcitrant 'Aboriginal problem' (Blagg 2008; Cripps 2004).

Aboriginal women and men continue to be affected by the traumatic legacy of historical institutional racism, expressed and reinforced by individual acts of racism by agents of the state. Conventional wisdom surrounding racial categories perpetuates discrimination and prejudice. Mainstream agencies continue to relate to Aboriginal women and men on the basis of racist stereotypes that are so familiar they are rarely challenged.

Institutional racism infuses domestic violence policy. Perpetrator treatments and crisis management systems have been based on Western interventions and imposed by social institutions in ways described by Indigenous writers as epistemic and post-colonial (Duran et al 1998). Western (white) theories of domestic violence have been increasingly challenged by Indigenous critics as tools for social control. Simplistic conventional solutions that exacerbate the problem include programs that pathologise Indigenous men, focus on parallel factors such as alcohol and drug abuse and treat violence as symptomatic of a general community deficiency. Duran concluded that authors maintain a definition of the problem that masks the issues of domination and subjugation, issues which must be considered given the historical context of this problem' (Duran et al 1998: 98).

The literature shows that Indigenous women dealing with agencies experience racism as an everyday occurrence (Baldry, Green \& Thorpe 2006; St. Jean \& Feagin 1998). 'One in five Indigenous women experienced discrimination and or racism in 2002' (Office for Women's Policy 2005: 58). In 2004, an inquiry into housing for Aboriginal people examined institutional racism and reported that 'Aboriginal women and children escaping domestic and/or family violence experience a higher degree of disadvantage 
than non-Aboriginal applicants' (Equal Opportunity Commission 2004: 179).

In an attempt to place Indigenous issues on policy agendas, activists have promoted and supported a politics of Indigenous identity. Pat O'Shane (1976), for example, showed how and why the primary concern for Aboriginal women was racism, not gender. Jackie Huggins (Huggins cited in Jones 2005) explaind that 'there are some issues where Indigenous women can form alliances with non-Indigenous women, but that the form of feminism that is available to Indigenous women is not the model they prefer. Instead, they have their own brand of feminism that's all-encompassing'. In short, Aboriginal women's writings have stressed as their primary struggle the survival of their people, the recognition of their cultural identity and what those needs dictate for government policy.

In this context gender discrimination becomes secondary to cultural identity. The extent to which this much-needed emphasis on institutional racism can sustain a gender analysis has been strongly debated. Stubbs (2004: 4), for example, abhorred the backlash against gender policy and argued that 'denouncing domestic violence as a crime has been an important gain of feminist acrivism after a history of neglect and should not be undermined'. Others have argued that neither gender nor race should be the primary focus, but rather how the two intersect in different situations. Led by black feminists in the United States, Crenshaw (1991) and Collins (1998), this concern for intersectionality has had very limited attention in Australian policy. It is that concern, coupled with the need to recognise the racism that underpins Aboriginal women's struggles, that provides the analytical starting point for this paper.

\section{RESEARCH METHODOLOGY}

Qualitative methodology was considered most appropriate to gather new information and a deeper understanding about gender and racism, contested fields of study. Exploratory in its design, the research sought to gain an understanding of how particular policy objectives are conceptualized as well as operationalised.

We used a case study approach and the techniques of literature review, policy audits, document analysis and interviews with a number of key players. Case study is valuable for gaining a greater depth of understanding of the topic (Yin 1989). The two case studies in this research were designed to provide triangulation for the research question of when and how gender and racism are rendered invisible. We used issues and themes arising from document analysis of the two case studies to develop the interview questions and analyse the transcripts. Both case studies analysed Western Australian policy documents and reports.

The first case study examined in-depth a major inquiry report to government (Gordon, Hallahan $\&$ Henry 2002). The Inquiry that developed the report was instituted by the Western Australian Government in 2001 as a response to media accounts of widespread sexual abuse and violence within the Aboriginal community. We selected the Inquiry for its significance as a major policy 'driver' for what it calls 'family violence' services specific to Aboriginal communities. We complemented content analysis of the 'Gordon Report' and other Inquiry publications by examining other relevant government documents. These included parliamentary debates, media statements, departmental policies and procedures concerning implementation plans and activities, operational guidelines for staff dealing with child protection and family violence, program outlines, implementation and evaluation reports.

Our second case study used a policy audit method. Techniques involved an initial meeting with senior policy staff, analysis of relevant policy documents, interviews with the staff who worked on drafting the policy, and a further meeting with this group to discuss and revise our policy audit draft report. Phone conversations and email communications were also sources of information.

The policy audit was undertaken during a review of the existing Government 'mainstream' 
FDV Policy in order to appreciate experiences and perspectives of policy actors during the development process. Commencing the policy audit process during policy review was an opportunity to learn about the early stages of the 'policy cycle' rather than following policy adoption and implementation. The policy audit was conducted as part of a larger Gender Analysis of Policy research project, the stated goal of which was to refine existing models and develop gender analysis processes appropriate for application in the Australian public sector context (Bacchi et al 2005).

Insights gained from semi-structured interviews as part of the policy audit contributed to a picture of the strategic thinking and motivations involved in policy development within that politicised environment. Interview questions were drawn from Status of Women Canada (2001) material to describe the policy context, question the extent to which the policy expresses intention to be gender-inclusive and culturally inclusive, and the extent the FDV policy achieved genderequitable and culturally-equitable outcomes.

\section{Case study one: 'Gordon Inquiry'}

The inquiry that we examine in our first case study is known colloquially as the 'Gordon Inquiry' because it was chaired by prominent Aboriginal magistrate Sue Gordon. The Inquiry was triggered by several incidents of sexual and physical abuse of Aboriginal children, which received significant media attention and resulted in a public outcry. The findings of a coronial inquest questioned Government services and professional practices and prompted Government action. Previous reports, Parliamentary debates and media profiles revealed a highly political policy context within which public servants were delivering services to vulnerable, disadvantaged Aboriginal communities. Prior to the Inquiry, independent research and government reports had criticised a range of structural, organizational, administrative and human resource factors impeding progress in responding to the needs and problems experienced by Aboriginal people.
The Gordon Inquiry worked within established Terms of Reference, with restricted time and resources, and in a climate of political and public pressure. The Committee of three heading the Inquiry received submissions, heard personal evidence, traveled throughout the State for consultations, drew on a comprehensive contracted literature review, and engaged in dialogue with key human service agencies. Their report (Gordon et al 2002) made over 190 recommendations for change to support successful local initiatives by Government at community level and to address perceived problems at agency level and across inter-agency structures.

The approach taken by the Inquiry reflected Aboriginal views that sustainability for Aboriginal peoples was dependent on finding ways to counter substantial intergenerational trauma, disadvantage and disempowerment in the face of white mainstream systems and practices that were destructive at their worst and negligent at their most benign. Dealing with substantial disadvantages was the challenge and theme throughout the report. The Inquiry had a mandate to examine public services that Aboriginal people identified as problematic, identify how the extensive disadvantages experienced by Aboriginal communities could be dealt with by mainstream agencies, and areas for reform of FDV services was the task (Gordon et al 2002: xx-xxi). The experiences of actual or potential Aboriginal FDV service users provided the material that informed recommendations for agency change. Public policy was viewed as having responsibility for Aboriginal disadvantage either directly or indirectly, immediately or historically; Aboriginal disadvantage was portrayed as being a causative factor which was intensified by FDV.

\section{Institutional racism}

The Inquiry reported that racism was one of multiple contributing factors to the endemic violence against Indigenous women and children. A composite account of institutional racism was provided by the Inquiry's examination of policy 
outcomes experienced by Indigenous clients. Intergenerational trauma was described as a legacy of colonization, genocide, dispossession, forced removal of children, loss of land, destruction of culture, and persistent racism. Indigenous communities were reported to have become increasingly vulnerable to symptomatic family violence and white government interventions, potentially more destructive than beneficial. Within the picture of violence in Aboriginal communities presented by the Inquiry, violence against women and children was perpetrated by potentially multiple abusers connected by extended family relationships located within the community. The Inquiry concluded that future policy and service developments required a coordinated and well-resourced, culturally sensitive system that would be increasingly under the direction, if not controlled, by Aboriginal peoples themselves (Gordon et al 2002; Kovacs 2002).

The Government strongly endorsed the major thrust of the Gordon Inquiry's report (Government of Western Australia 2002). Subsequently, over a period of four years, Treasury injected major funding to the key agencies to implement recommendations for program initiatives, infrastructure development, and departmental projects to strengthen service delivery (Gallop 2002). Interim evaluations have been critical of implementation progress and monitoring, and comprehensive evaluations are underway (Auditor General for Western Australia 2005).

\section{Gender dimensions of FDV in Indigenous communities}

In making its recommendations, the Committee encouraged human service agencies to ensure cross-cultural sensitivity and develop inclusive practices, such as promoting the language of family and community instead of violence against women. The report noted that for Aboriginal women and men, white mainstream agencies delivered FDV policy that effectively denied the history of oppression, genocide and systemic abuse of Aboriginal people. It also acknowledged that ethnocentric definitions, understandings and approaches created difficulties for intervening in family violence in Aboriginal communities.

There were two elements of FDV policy that the Inquiry did not examine: (a) the structural arrangements whereby public sector institutions operate as systems of social control to protect and perpetuate inequalities, and (b) the intersections of gender and racism in family violence policy and what they might mean for that policy's capacity to protect Aboriginal women.

The Inquiry's conclusions drew on a growing body of literature by Indigenous authors, especially Aboriginal women, which reveals the history of sexualised racist abuse by Anglo-Australians since white settlement and rebukes the role of the state and its agents for white ethnocentricity. In turn, several Aboriginal women who spoke to the Inquiry rejected mainstream approaches that individualised social problems, arguing that these further victimised the whole Aboriginal community, criminalised Aboriginal men and indirectly blamed Aboriginal women for the violence they suffered.

In the light of such discussions, those leading the Gordon Inquiry decided to adopt the terminology of 'family violence' in place of the usual 'domestic violence'. However, this shift in terminology did not altogether resolve the definitional problems, and indeed raised voices of concern from Aboriginal women. These were subsequently reported in the community consultations: 'I would prefer to see family/domestic violence called "Violence against Women". "Family Violence" makes it sound nice!' (Gordon et al: 29).

In dealing with this debate among Aboriginal women the report of the Inquiry added an appendix showing how definitions differed across Australia, and in the FDV sector, organizations and sections within agencies. The report advised that in light of these wide variations in terminology and categories used there was a call for a term which could capture the need to respect Indigenous calls for a focus on the broader experience of violence within extended Indigenous families 
(Gordon et al July 2002: 29). 'For many Indigenous people the term family violence is preferred as it encompasses all forms of violence in intimate, family and other relationships of mutual obligation and support' (Gordon et al July 2002: 26). The report also argued for a singular, shared definition for the purpose of ensuring 'collaborative and coordinated responses' (Gordon et al July 2002: 27).

\section{Case study two: Western Australian Family and Domestic Violence Policy}

The FDV Policy was intended to provide a framework for the guidance of department staff and the development of responses to individuals, families and communities affected by family and domestic violence. From the framework would follow documentation for policy implementation including departmental operational guidelines and training manuals. The department involved carries responsibility for policy coordination across human services agencies. Unlike the Gordon Inquiry analysed above, the FDV Policy is not meant to provide a vehicle for the department to influence the broader FDV field (including inter-governmental, inter-departmental and the community services sector). Rather, it establishes the principles for how a department internally works with family and domestic violence. To establish what was needed for this task, the policy group drew on documents that had been available in the field for some years to outline principles for 'best practice' in service delivery across government and non-government organizations.

The policy development process was conducted according to a schedule of regular policy reviews across government departments. The review and development process updates and amends policies to reflect best practice developments, provide for changes such as organizational and structural requirements, meet new service needs and take account of expectations for policy responsivity and accountability. The FDV Policy was initially developed in 1996 . A relatively limited review was undertaken in 2000 , so a substantial revision of the Policy was involved in 20052006. The goal was to meet the requirements of recent legislative reform and to be forward thinking with holistic policy that was informed by the latest statistical data and research. Injecting more evidence and information into policy and practice has become more important in response to an increasingly 'audit culture' (Power 1999), where measurement and accountability identifies particular outcomes.

The political environment within which policy development took place was of primary importance to the review. The department's strategic plan reflected the breadth of focus and challenge of new directions experienced by the department from Government planning, new legislation, implementation of new policies and a new Indigenous 'vision'. The department's structure reflected the wide range of functions and a number of policy units informed and supported the work of core regional and local fieldwork.

In tune with a government sensitive to media coverage of child abuse, most intense visibility was directed at children's welfare. Accountability for the agency against a primary objective of child protection was producing considerable pressure on department staff across functional areas. The department's service delivery based on community development approaches was being challenged by calls for a 'law and order' response that required increased crisis intervention with casework. The 'best practice' model for programs for victims of domestic violence had been criticized for its 'colour blindness', and policy development that considered Aboriginal perspectives was called for by the FDV field (HREOC 2002). And many departments were facing the challenge of allocating FDV funds to meet increasing demands for perpetrator education and violence prevention programs on the one hand and the needs of ongoing and new refuge and victim services for women on the other. The intensity of political sensitivity and media scrutiny created a degree 
of vulnerability and anxiety that affected the policy development. Subsequent to the case study period, the department experienced considerable instability with repeated restructuring and staff changes at the senior levels.

Some years earlier, observers viewed the forerunner of this department as dealing with 'women's issues' as a major part of its agenda. In the current climate, government departments had adopted a strategic approach and terminology of 'gender neutrality'. Consequently, the gender focus of policies across the department has in most cases been implicit rather than explicit. Policy actors expressed awareness of the need to be strategic in promoting particular concepts and approaches to specific audiences and participants in the policy process. A number of gender-based insights drive the department's operations, and it was explained that the high level policies need to be deliberately broad in order to allow for gender as well as other kinds of diversity to be taken into account at the point of implementation.

Within this context, FDV policy was presented as 'even-handed' to achieve a 'political balance' in policy statements. The approach was designed for public reassurance using policy language that was carefully pitched to sustain a gender-neutral tone. Policymakers explained during interviews that 'more ambiguous or neutral terms ... would enable current trends and findings to shape the services'. References are made in policy documents to 'individuals', 'families', 'communities' and 'young people'. The department's charter was presented in a way that was deemed acceptable to the broader community, that is, as inclusive (of men) rather than being concerned exclusively or predominantly with women's issues and needs. A focus on domestic violence which had come to signify violence against women was shifted over time to a broader focus onto family and domestic violence. The policy document states that FDV 'impacts on all sections of the community, cutting across race, gender, age and social status'. The shift was explained as the department's responsiveness to feedback from Aboriginal women
(Hovane 2006; Nancarrow 2006) and advice from government Aboriginal policy experts.

Despite this apparent concern for culturally sensirive policy, the Gordon Inquiry did not feature in the FDV Policy review. Nor was the Inquiry and its recommendations raised as a policy driver by the policy actors in discussions, interviews or documentation. The fact that such a major inquiry, which was being implemented during the period of the audit, did not feature prominently during the review could be seen as indicative of functional separation. Here was a major inquiry into FDV in Aboriginal communities, but it did not immediately provide a backdrop for policy actors reviewing existing policy statements. Rather, political and agency imperatives shaped the framework for policy review. Yet the lack of integration within and across agencies, policy and services was a central conclusion reached by the Gordon Inquiry, and one that its implementation was meant to challenge. We might conclude that the policy process seen within the department during the FDV Policy audit could be considered an example of that compartmentalisation.

Given the gender-neutrality of high level policy, these policy actors saw their task was to effectively translate abstract policy statements into the tacit understandings of gender and diversity dynamics so that implementation is sufficiently equipped for FDV service delivery. What may be understood implicitly by experienced senior policy drafters needs to be effectively communicated to operational staff.

However, the fact that the department identifies itself first and foremost as a child protection system, has particular implications for that capacity to translate gender-neutrality into effective FDV implementation. To the extent that gender relations are considered, paramount attention is to the care and safety of the children in situations of FDV. Here the primary focus on women and men is not as battered and batterers in domestic violence situations, but as ungendered and porentially dangerous parents and ineffective carers as 
part of risk aversion priorities in child protection work. Thus the capacity of frontline staff to meet service expectations and deliver policy goals may be weakened by policy concepts and language that render gendered power relations invisible and cultural sensitivity an empty promise.

\section{DISCUSSION}

Our study shows that the field of FDV is politically sensitive. In such an environment the high profile and sharp criticism accorded government intervention means policy actors adopt ways and means to do their work that will bring them as little public attention as possible. The case studies show how power dimensions in gendered relationships as well as those in institutional racism, can be rendered invisible through the daily reality of work in public policy development. In trying to highlight how white racism produced the bedrock of FDV in Aboriginal communities, the Gordon Inquiry submerges the gendered power relations underpinning contemporary violence against women and children. In trying to meet the need for an overriding child protection agen$\mathrm{da}$, the FDV Policy makes gender and gendered power relations at best implicit and at worst irrelevant and outdated. That Policy also shows that when the emphasis is not on institurionalised racism, then the discussion of racism as an aspect of policy also goes missing.

In the Gordon Inquiry the unintended consequence of defining the violence against women in 'inclusive' ways represented a lost opportunity to investigate gendered power relations involved in processes and interactions (eg between women and men at interpersonal points of connection) within the wider community and in relation to state interventions. The Inquiry did not look at the dynamics, complexities and impacts of gendered power relations on community leadership as affected by FDV, or at how those relations might affect patterns of family responsibilities and obligations for caring, law and education practices and a host of cultural traditions and ceremonies.
By not focusing on gendered power relations involved in the violence between women and men, the Gordon report effectively represented all the different forms of violence being experienced in Aboriginal communities as indistinguishable. The inference was that all forms of violence operated on the same plane in terms of occurrence, severity and consequences. Some Aboriginal women warned the Inquiry that opting for a single definition of 'family violence' risked losing sight of the damage being done to women. By failing to show how 'family violence' could incorporate an understanding of the ways in which racism intersects with gender, the Gordon report deflected attention from the power differentials based on gendered notions of masculinity and femininity, roles and responsibilities.

Blagg (2007) argued that reaching agreement on a single definition is inappropriate and homogenizing of Aboriginal peoples:

Let us dispense with the notion that there is, or can be, a unitary definition of family violence and explore the construct in its diversity. There is no settled, one-fits-all definition and the meanings associated with the term shift from region to region in the light of local history, circumstances and concerns. They can also shift over time as new issues emerge.

(Blagg 2007: 10)

Taking account of gender, Pease and Camilleri (2001) argued that a 'one size fits all' definition that captures a range of forms and relationships within families and communities hides the reality that overwhelmingly women are the victims of male violence. Domestic violence is the most common form of violence perpetrated against women (United Nations Population Fund 2005: 66) Statistical evidence confirms what Bolger (1991) and other writers have revealed for years that the most common form of violence taking place in Aboriginal communities is violence against women who are most at risk from their husband/spouse/partner. 
The department which instituted the revised FDV Policy also missed an opportunity to get to the heart of the problem. This department is well-placed with its leadership role within the larger policy framework of whole-of-government responses to FDV to influence wider public policy. By opting for a gender-neutral approach, the department's high level FDV Policy falls silent on the issue of women's greater vulnerability. Rhonda Sharp and Ray Broomhill (1988) argued that most claims to be gender-neutral are indeed gender blind. A gender-neutral policy approach that assumes that women and men are affected by policies in the same way is inadequate for FDV where the consequences of not explicitly analyzing gender relations can be a life and death matter. The stance taken could inadvertently weaken or undermine the capacity of the department to deliver gender sensitive field services. Connell (2006: 449) has noted that the principal goal of a gender-neutral public sector workplace limits the state's steering capacity in regard to societal gender relations.

Although experienced feminist policymakers may fully intend to rectify this façade of genderneutrality by ensuring that the operational guidelines are sufficiently gender specific, that solution must be unreliable in terms of dealing with a vast majority of cases, inevitably short-term in an ageing labour market, and destined to dissolve without structural backup and leadership direction. Moreover, if the department presents its policies as gender neutral, it could be assumed that the department operates internally as gender blind.

The potential dangers of poorly informed public policy and broad definitions that disguise vulnerability predictably fall upon Aboriginal women and their children. Interventions that can be equally directed to elder abuse will fail to address the gendered nature of FDV, described by David Indermaur (2006) as 'domestic terrorism'. Donaghy (2003) criticised the lack of informed decision-making when gender-disaggregated statistics are available but largely underutilized in policy development, and the United Nations reported that data collection on this topic remains largely ad hoc and has not been incorporated into the regular statistical work programs of national statistical offices (Grown 2007: 205). Kurz (1993) criticised definitions of violence that fail to show how the context of domestic violence is the inequality and power differences between women and men.

Intersectionality (Crenshaw 1991) would offer a more inclusive approach to policy development by enabling the multiplicity of connections to be addressed simultaneously. The moral and political imperatives prompting and guiding intersectionality theory also lead us to conclude that the two policy developments we describe here are quite different in terms of their capacity to put institutionalized racism under the spotlight in domestic violence discussions. The Gordon Inquiry confronts head-on the contemporary race relations that render past and present racism invisible in domestic violence policy, and it draws on those with expertise in critical race theory and practice in order to do so. There is no sign of such theory, practice or indeed intervention by Indigenous women into past policy inadequacies evident in the Western Australian Government's FDV Policy Framework. Indeed, since the interviews with policy actors in this study indicated, they experienced a degree of anxiety about the concepts of gender and racism (and their relevance in terms of agency and government priorities). It would seem that much more needs to be done to bring the processes and insights of the Gordon Inquiry into everyday policy development.

The present study intimates that policy domains that are traditionally reactive, subject to backlash from political and community directions, and imbued with unrecognised institutional racism will provide at best limited support for the gender and racialised dimensions of FDV to be adequately seen and challenged. The promise initiated with the Gordon Inquiry shows that this fear and neglect does not have to remain the case. There is already evidence in the Western Australian context that, in other policy fields, inter- 
ventionist efforts by Indigenous women have produced a collaborative approach to challenging and reshaping the particular context of culture and community in which they need to operate. It is through such collaborations, designed to make the best of local experience and knowledge, that Aboriginal women can begin to realize their political, economic and community goals (Eveline, Bacchi \& Binns 2009). For future research in domestic violence policy what these case studies suggest is that more attention be paid to how mainstream policy actors can support the lead taken by discrete and experienced Indigenous women's groups in their endeavours to combat domestic violence.

\section{Acknowledgements}

The authors wish to acknowledge the Australia Research Council (ARC) for providing the funds for this study, and the government departments and policy actors who collaborated in this research. We thank also the anonymous reviewers who engaged with this paper and gave helpful suggestions for revision.

\section{References}

Aboriginal \& Torres Strait Islander Social Justice Commissioner Human Rights \& Equal Opportunities Commission (HREOC) (2007) 2007 Social Justice Report. HREOC, Canberra ACT.

Australian Law Reform Commission (ALRC) (1994) Equality Before the Law: Justice for Women, Vol 69 Part 1. ALRC, Canberra ACT.

Auditor General for Western Australia (2005) Progress with Implementing the Response to the Gordon Inquiry, Report 11, November 2005. Government of Western Australia, Perth, Western Australia.

Bacchi CL (2005) Policy, in Essed P, Goldberg DT and Kobayashi A (Eds) A Companion to Gender Studies, pp 181-191. Blackwell Publishing, Malden MA.

Bacchi C, Eveline J, Binns J, Mackenzie C and Harwood S (2005) Gender analysis and social change: Testing the water. Policy and Politics 24(4): 45-67.

Baldry E, Green S and Thorpe K (2006) Urban Australian Aboriginal peoples' experience of human services. International Social Work 49(3): 364-375.
Blagg H (2007) Zero tolerance or community justice? The role of the Aboriginal domain in reducing family violence. Paper: Queensland Centre for Domestic and Family Violence Research Conference 'Breaking the Chains - Reclaiming our Future', 2-3 May, Mackay, Queensland.

Blagg H (2008) Crime, Aboriginality and the Decolonisation of Justice. Hawkins, Sydney NSW.

Bolger A (1991) Aboriginal women and violence: $A$ report for the Criminology Research Council and the Northern Territory Commissioner of Police. Australian National University North Australia Research Unit, Darwin, Northern Territory.

Collins PH (1998) It's all in the family: Intersections of gender, race, and nation. Hypatia 13(3): 62-82.

Connell R (2006) The experience of gender change in public sector organizations. Gender, Work and Organization 13(5): 435-452.

Crenshaw K (1991) Mapping the margins: intersectionality, identity politics, and violence against women of color. Stanford Law Review 43(6): 1241-1299.

Cripps K (2007, 18 March) Indigenous violence. Interview with Karen Dorante on Speaking Out program, ABC Radio Message Stick, accessed at http://www.abc.net.au/message/radio/speaking/st ories/s1874310.htm on 18 April 2007.

Cripps K (2004) Enough Family Fighting: Indigenous Community Responses to Addressing Family Violence in Australia and the United States. Unpublished Doctoral Thesis, Monash University, Vicroria.

Donaghy DTB (2003) Gender and public policy making in Australia: The Howard Government's big fat lie. Paper: Australasian Political Studies Association Conference, 29 September-1 October, University of Tasmania, Hobart.

Duff C (1994) Racism, sexism and white feminism. Polemic 5(1): 36-40.

Duran E, Duran B, Woodis W and Woodis P (1998) A postcolonial perspective on domestic violence in Indian country, in Carrillo R and Tello J (Eds) Family Violence and Men of Color: Healing the Wounded Male Spirit, pp 95-113. Springer, New York.

Equal Opportunity Commission (2004) An Inquiry into the Existence of Discriminatory Practices in Relation to the Provision of Public Housing and Related Services to Aboriginal People in Western Australia. Government of Western Australia, Perth.

Eveline J and Bacchi CL (2005) What are we mainstreaming when we mainstream gender? International Feminist Journal of Politics 7(4): 496-512. 
Eveline J, Bacchi C and Binns J (2009) Gender mainstreaming versus diversity mainstreaming: Methodology as emancipatory politics. Gender, Work and Organization 16(2): in press.

Ferrante A, Morgan F, Indermaur D and Harding R (1996) Measuring the Extent of Domestic Violence. Hawkins Press, Perth, Western Australia.

Gallop G (2002) Government commits \$75million to combat child abuse and family violence in Aboriginal communities. Media Statement by the Premier, 3 December 2002, Government of Western Australia, Perth.

Gordon S, Hallahan K and Henry D (July 2002) Putting the Picture Together: Inquiry into Response by Government Agencies to Complaints of Family Violence and Child Abuse in Aboriginal Communities. Government of Western Australia, Perth, Western Australia.

Government of Western Australia (2002, November) Putting People First: The Western Australian State Government's Action Plan for Addressing Family Violence and Child Abuse in Aboriginal Communities. Government of Western Australia, Perth, Western Australia.

Grown CA (2007) Gender Equality: Striving for Justice in an Unequal World. Review of Gender equality: Striving for justice in an unequal world; Progress of the world's women 2005: Women, work, and poverty; and The world's women 2005: Progress in statistics. Feminist Economics 13(2): 203-207.

Hovane V (2006) White privilege and the fiction of colour blindness: Implications for best practice standards for Aboriginal victims of family violence. Australian Domestic and Family Violence Clearinghouse (27): 8-12.

Indermaur D (2006) Domestic terrorism. Paper: Family and Domestic Violence Unit Breakfast event at the Perth Town Hall for White Ribbon Day, 25 November, Perth, Western Australia.

Jones R (2005) What is the status of Indigenous women and Indigenous feminism in Australia? Accessed at http://www.awid.org/go.php?stid $=1454$ on 29 May 2007.

Kovacs K (2002) Overview of the Gordon Report. National Child Protection Clearinghouse Newsletter 10(2). Australian Institute of Family Studies (AIFS), Melbourne, Victoria.

Kurz D (1993) Social science perspectives on wife abuse: Current debates and future directions, in Bart PB and Moran EG (Eds) Violence Against Women: The Bloody Footprints, pp 252-269. Sage, Newbury Park CA.

Nancarrow H (2006) In search of justice for domestic and family violence: Indigenous and non-
Indigenous Australian women's perspectives. Theoretical Criminology 10(1): 87-106.

Office for Women's Policy (2005) Indigenous Women's Report Card 2005: Supplement to the Women's Report Card. Department for Community Development, Perth, Western Australia.

Office for Women's Policy (2006) Indigenous Women's Report Card: Summary 2006. Department for Community Development, Perth, Western Australia.

O'Shane P (1976) Is there any relevance in the women's movement for Aboriginal women? Refractory Girl 12: 31-34.

Partnerships Against Domestic Violence (2001) Rekindling family relationships: A national forum on Indigenous family violence, 9-11 April 2001. Commonwealth of Australia, Canberra.

Pease B and Camilleri P (Eds) (2001) Working with Men in the Human Services. Allen \& Unwin, Crows Nest NSW.

Power M (1999) The Audit Society: Rituals of Verification. Oxford University Press, Oxford/New York.

Sharp R and Broomhill R (1988) Short-changed: Women and Economic Policies. Allen \& Unwin, Sydney NSW.

St. Jean Y and Feagin JR (1998) Double Burden: Black Women and Everyday Racism. ME Sharpe, Armonk, NY/London.

Status of Women Canada (2001) Gender-based Analysis (GBA) Policy Training: Participant Handbook. Government of Canada.

Stubbs J (2004) Restorative justice, domestic violence and family violence. Australian Domestic and Family Violence Clearinghouse, Issue Paper 9. University of NSW, Sydney.

Templeman D (2006) 'No more violence - we're breaking the silence' program: Statement by Minister for Community Development. Accessed at http://www.parliament.wa.gov.au on 9 May 2007.

United Nations Population Fund (UNPF) (2005) The State of the World's Population. UNFPA, New York.

Walby S (2005) Gender mainstreaming: Productive tensions in theory and practice. Social Politics: International Studies in Gender, State and Society 12(3): 321-343.

World Health Organization (WHO) (2005) WHO Multi-country Study on Women's Health and Domestic Violence Against Women: Initial Results of Prevalence, Health Outcomes and Women's Responses, Summary Report. WHO, Geneva.

Yin RK (1989) Case Study Research, Design and Methods. Sage, Newbury Park CA. 
Copyright of Journal of Family Studies is the property of eContent Management Pty. Ltd. and its content may not be copied or emailed to multiple sites or posted to a listserv without the copyright holder's express written permission. However, users may print, download, or email articles for individual use. 